\title{
PENINGKATAN STRATEGI PEMASARAN SHOPPE DALAM BISNIS INTERNASIONAL
}

\section{Sherina Said Mazruk, Nuri Aslami}

Universitas Islam Negeri (UIN) Sumatera Utara, Medan, Indonesia

Email: sherinasaidmazruk1120@gmail.com,nuriaslami@uinsu.ac.id

\begin{tabular}{|c|c|}
\hline & \\
\hline & \multirow{12}{*}{$\begin{array}{l}\text { Perkembangan teknologi informaasi telah mengubah gaya hidup } \\
\text { masyarakat dan menciptakan ekonomi modern. Tinggi minat } \\
\text { berbelanja dengan menggunakan E-Commerce membuat Shopee } \\
\text { melakukan perkembangan strategi pemasaran internasional sebagai } \\
\text { upaya untuk meraih kesuksesan dalam bisnis internasional. Penelitian } \\
\text { ini menggunakan metode kualitatif dengan pendekatan deskriptif. } \\
\text { Pengumpulan data sekunder diperoleh dengan teknik pengumpulan } \\
\text { data studi literatur yang bersumber pada berbagai dokumen seperti } \\
\text { buku dan jurnal ilmiah.Penelitian ini bertujuan untuk mengetahui } \\
\text { perkembangan strategi pemasaran Shopee dalam bisnis internasional. } \\
\text { Dalam hasil penelitian ditemukan bahwa Shopee menerapkan } \\
\text { kombinasi pull dan push strategy untuk meningkatkan loyalitas } \\
\text { pelanggan. }\end{array}$} \\
\hline & \\
\hline & \\
\hline & \\
\hline & \\
\hline & \\
\hline & \\
\hline & \\
\hline & \\
\hline & \\
\hline & \\
\hline & \\
\hline
\end{tabular}

Keywords:

International

Business; Marketing

Public Relations

Strategy; Shopee;

Marketing Strategy

\section{ABSTRACT}

The development of information technology has changed people's lifestyles and created a modern economy. High interest in shopping using E-Commerce makes Shopee develop international marketing strategies in an effort to achieve success in international business. This research uses qualitative methods with a descriptive approach. Secondary data collection is obtained by data collection techniques of literature studies sourced on various documents such as books and scientific journals. This research aims to find out the development of Shopee's marketing strategy in international business. The results of the study found that Shopee applies a combination of pull and push strategy to increase customer loyalty.

\section{Pendahuluan}

Perkembangan zaman yang terus mengalami kemajuan lambat laun mengubah gaya hidup masyarakat. Pada zaman sekarang ini, gaya hidup masyarakat semakin serba instan dikarenakan mayoritas masyarakat memiliki mobilitas yang tinggi dalam kegiatan sehari -harinya (Fonna, 2019). Revolusi Industri 4.0 sebagai dampak dari perubahan global memfasilitasi masyarakat untuk dapat mengakses berbagai macam informasi dengan menggunakan internet (Syamsuar \& Reflianto, 2019). Internet memiliki dampak yang luas terhadap kehidupan masyrakat sekarang ini. Pemanfaatan internet dan perkembangan teknologi informasi dapat membantu mengembangkan sifat penyediaan layanan dan turut memberikan suatu pengaruh terhadap proses perubahan penyediaan jasa. Kolaborasi keduanya juga mendorong brtumbuhnya bisnis electronic commerce atau

$\begin{array}{ll}\text { How to cite: } & \text { Mazruk, Sherina Said, Nuri Aslami (2022). Peningkatan Strategi Pemasaran Shoppe Dalam Bisnis } \\ & \text { Internasional, Action Research Literate, 6(1). } \\ \text { E-ISSN: } & 2721-2769 \\ \text { Published by: } & \text { Ridwan Institute }\end{array}$


E-Commerce. Menurut Kotler dan Amstrong dalam (Pradana, 2017) E-Commerce adalah saluran online yang dapat dijangkau seorang pebisnis untuk melakukan aktifitas bisnisnya dan digunakan konsumen untuk mendapatkan informasi. E- Commerce dapat dimanfaatkan sebagai media perukaran barang dan jasa baik secara antar intitusi atau Business to Business (B2B) maupun antara perusahaan dengan konseumen secara langsung atau Business to Customer (B2C).

Menurut (Ramadhania \& Anisab, 2021) shopee merupakan salah satu pusat perbelanjaan elektronik yang resmi sejak tahun 2015. Sebagai salah satu E-Commerce terkenal asal Singapura, Shopee juga merasakan adanya pertumbuhan berbagai ECommerce dari tahun ke tahun yang diiringi dengan perkembangan teknologi.. Tak lama kemudian, Shopee dengan cepat memperluas ruang lingkup bisnisnya dengan meluncurkan produk di beberapa negara seperti Indonesia, Malaysia, Thailand, Taiwan Vietnam, dan Filipina. Dilansir dari (Yosepha Pusparisa, 2020) Shopee dinobatkan sebagai situs ECommerce yang berhasil menarik pengunjung terbanyak se-Asia Tenggara. Shopee menarik sekitar 2,1 miliar pengunjung online pada tahun 2019. Untuk dapat meraih hal tersebut Shopee berkonsentrasi pada strategi pemasaran perusahaan. Pemasaran sejatinya merupakan visi dan misi perusahaan di masa depan. Pemasaran dapat berkontribusi pada persepsi kinerja hubungan pelanggan, keuangan yang kokoh, dan kinerja produk baru di luar interpretasi yang digerakkan oleh pasar. Pemasaran internasional diartikan sebagai praktik bisnis yang merencanakan, memberi harga, dan mempromosikan barang dan jasa kepada pelanggan di lebih dari satu negara untuk menciptakan keuntungan. Pemasaran internasional berperan sangat penting dalam melakukan penelitian, peramalan, dan perancangan strategi untuk penjualan produk di pasar negara tujuan.
Strategi internasional adalah strategi bisnis internasional perusahaan yang menerapkan strategi bisnis di pasar domestik dan luar negeri dengan membaca peluang, dimana pesaing- pesaing lokal tidak memilikinya. Thomas L. Harris mengatakan bahwa banyak strategi yang dapat diterapkan melalui strategi marketing public relations strategy A to Z (HARIS, 2012). Perpaduan antara marketing public relation dengan periklanan dapat meningkatkan hasil yang ingin dicapai serta dapat efektif dalam membangun brand awareness dan brand knowledge.

\section{Metode Penelitian}

Penelitian ini menggunkan metode kualitatif dengan pendekatan deskriptif (Sholikhah, 2016). Penelitian ini didasarkan pada pengumpulan data sekunder dengan teknik pengumpulan data yang digunakan adalah studi literatur. Studi literatur adalah teknik pengumpulan data yang dilakukan dengan mengumpulkan data dan informasi dari berbagai dokumen seperti buku, gambar, jurnal ilmiah, hingga dokumen elektronik lainnya yang dapat memperkuat pernyataan tertentu dalam sebuah penelitian (Sugiyono, 2012). Kumpulan data studi literatur yang terdiri dari artikel jurnal dan textbook sebagai tulisan yang pernah dibuat sebelumnya, dijadikan sumber untuk menyelesaikan persoalan. Pengumpulan studi literatur digunakan dengan bebrapa tahapan diantaranya adalah pencarian artikel berdasarkan relevansi dengan topik dan tahun penelitian, kemudian melakukan pengurutan struktur penjelasan.

\section{Hasil dan Pembahasan}

\section{A. Hasil Penelitian}

Shopee telah menerapkan beberapa langkah pemasaran dalam menunjang bisnis internasionalnya, diantaranya seperti garansi Shopee, gratis ongkir, garansi harga termurah, dan kampanye Big 
Mobile Shopping Day. Selain itu, pada tanggal 6 Juni 2019 Shopee telah resmi meluncurkan beragam fitur terbaru, salah satunya Shopee Live. Melalui fungsi siaran langsung ini, pelanggan dapat lebih mudah mengajukan berbagai pertanyaan terkait produk yang ditampilkan oleh pesnjual. Tidak hanya itu, pengguna yang berminat membeli produk yang ditampilkan jugabisa langsung membeli produk terkait mellaui fungsi keranjang belanja di siaran langsung. Tak hanya itu, semua siaran langsung yang telah berakhir dapat diputar dan diakses kembali melalui akun masing - masing penjual.

Dengan perkembangan bisnis melalui proyek Shopee Live, kini Shopee Live telah meluncurkan program baru bernama "Shopee Streamer Academy" yang memungkinkan pengguna juga melakukan streaming secara real-time di Shopee Live. Shopee Streamer Academy dikembangkan oleh tim User Generated Content (UGC). Adanya Shopee Streamer Academy ini, para streamers akan mendapat keuntungan seperti insentif dan jenjang karir. Dalam hal ini, media streaming dapat meningkatkan kreativitas untuk membuuat dan mengembangkan konten yang ditampilkan melalui siaran langsung. Shopee Streamer Academy membuat kriteria penialaian agar streamers dapat termotivasi. Para streamers harus memenuhi beberapa indikator seperti jumlah penonton; likes; durasi penonton yang menonton livestream; serta kuantitas dan harga produk yang ditampilkandan berhasil dipesan oleh penonton selama siaran langsung. Menurut perhitungan insentif Shopee Streamer Academy untuk keempat indikator ini per 18 Juni 2020, streamer akan menerima Rp25 per satu penonton; Rp1 untuk setiap 10 likes; setiap penonton yang menyaksikan siara langsung selama1 menit streamer mendapat Rp50; dan 10\% dari harga produk yang berhasil dipesan oleh penonton selama siaran langsung.

B. Pembahasan

Shopee menggunakan kombinasi pull strategy dan pass strategy dalam penerapan marketing public relations melalui program Shopee Streamer Academy (Ramadhani ${ }^{a}$ \& Anisab, 2021). Pull strategy disini diterapkan dengan menitikberatkan pemanfaatan iklan dan aktivitas promosi kepada konsumen dengan tujuan merangsang, meningkatkan permintaan (demand) konsemen, dan membangun loyalitas konsumen terhadap produk (Ruslan, 2010) dalam (Widuhung, 2021). Shopee sebagai sebuah ECommerce mendorong konsumen (khususnya pengguna aplikasi Shopee) untuk melakukan pembelian produk dengan cara menciptakan ketertarikan konsumen terhadap produk dengan cara menampilkan sajian konten menarik yang telah dibuat oleh para streamers. Streamers yang tergabung dalam Shopee Streamer Academy akan dilatih dan dididik oleh UCG Team agar memiliki keterampilan pengemasan konten seperti influencer handal. Meskipun Shopee Streamer Academy bukanlah program yang memasukkan kegiatan komunitas, namun hal ini tetap sejalan dengan interpretasi Rosady Ruslan yang mendefinisikan pass strategy sebagai strategi yang menekankan keikutsertaan perusahaan atau produsen dalam kegiatan yang melibatkan beberapa gatekeepers untuk menciptakan atau mempengaruhi opini publik yang bermanfaat bagi perusahaan. Para streamers-lah yang berfungsi menghubungkan antara perusahaan dengan konsumen. Selain itu, streamers sebagai pihak luar juga membantu perusahaan untuk meningkatkan opini publik khususnya terkait produk - produk yang berhubungan dengan konten yang dibahas dan dibeli melalui aplikasi Shopee. 
Berdasarkan konsep marketing publik relations strategy $A$ to $Z$ yang dicetuskan oleh Thomas L. Harris, Shopee menerapkan tiga jenis taktik, yaitu competitions, demonstrations, dan product placement (Azlina, 2018). Kompetisi atau competitions adalah persaingan oleh sejumlah partisipan untuk memperoleh sesuatu. Public relations yang memanfaatkan strategi kompetisi dalam melakukan promosi akan memperoleh berbagai manfaat, diantaranya adalah meningkatkan ketertarikan publik terhadap aksi promosi; menambah relasi; dan menjalin hubungan baik dengan publik melalui pemberian hadiah atau penghargaan kepada partisipan yang menjadi pemennag kompetisi. Dalam penerapannya, Shopee menyelenggarakan KPOP Stream Competition apa tanggal 20-26 Juni 2020 dalam rangka memeriahkan penanyangan KCON: TACT 2020 Summer di Shopee Live. KCON: TACT 2020 merupakan festival musik pop Korea atau Korean Pop (K-Pop) yang disiarkan online melalui platform livestreaming yang dimerihakn bebrapa artis Korea ternama seperti GFRIEND, Chungha, ITZY, Monsta X, dan lain sebagainya. Dalam event tersebut Shopee mengadakan kompetisi siaran langsung di Shopee Live yang bertema kultur Korea untuk meningkatkan antusiasme penggemar K-Pop di Indonesia. Jenis taktik kedua adalah demonstrations yang diterapkan Shopee dengan memfasilitasi streamers untuk merepresentasikan pemakaian atau penggunaan produk tertentu dengan menggunakan sudut pandang sebagai seorang konsumen. Terakhir, Shopee juga menerapkan taktik product placement. Karrh mendefinisikan product placement sebagai penyisipan produk dari brand tertentu dengan memanfaatkan audio, audiovisual, maupun visual melalui platform media massa
(Karrh, 1998). Product placement dibangun dengan tiga komponen. Pertama, screen placement untuk menampilkan brand secara visual seperti advertising banner di jalan raya. Kedua, script placement yaitu dialog yang menggambarkan brand. Ketiga, plot placement yang membangun alur cerita. Dalam Shopee Live, ketiga prinsip ini diterapkan ketika seorang streamers melakukan konten product review.

Strategi pemasaran yang telah diatur sedemikian rupa hendaknya diiringi pula dengan strategi pelayanan bagi konsumen. Kualitas pelayanan adalah penentu bagi kepuasan pelanggan. Aplikasi ECommerce hendaknya menyediakan informasi yang memadai baik berupa informasi mengenai spesifikasi produknya, promosinya, macam-macam produknya, serta bagaimana sistem pembayarannya. Aplikasi juga baiknya menyediakan pelayanan berupa sarana untuk menjawab pertanyaan - pertanyaan pelanggan dengan cepat. Ketika pertanyaan pertanyaan pelanggan mampu dijawab dengan cepat, maka mereka merasa terlayani dengan baik sehingga mereka dapat terpuaskan. Kemudahan dalam proses pemesanan juga menjadi hal yang penting. Pelanggan akan merasa senang membeli pada E-Commerce karena adanya kemudahan dan kesesuaian harapan dalam proses pemesanan. Terkait perihal tersebut, Shopee memudahkan konsumen untuk dapat memesan produk yang mereka sukai ketika sedang menonton Shopee Live. Terdapat fitur shopping cart atau yang disebut dengan keranjang belanja yang mempermudah penonton dan streamers menandai produk ketika sedang siaran langsung. Fitur ini digunakan streamers untuk menyisipkan beragam produk yang berhubungan dengan konten yang dibahas ke dalam siaran langsung. Sedangkan untuk penonton, fitur ini dapat 
digunakan untuk mengetahui produk beserta harga yang ditawarkan di Shopee. Penonton juga dapat langsung membeli produk yang sedang ditayangkan tanpa harus keluar dari beranda siaran langsung, ini akan memberi keuntungan serta kemudahan pembelian produk pada penonton apalagi ketika sedang penayangan konten yang memuat produk flash sale.

Semua yang telah dilakukan Shopee merupakan strategi pemasaran internasional sebagai upaya dalam kegiatan bisnis internasional. Strategi pemasaran internasional dirancang untuk meningkatkan kinerja pemasaran internasional. Strategi pemasaran internasional berdampak pada peningkatan reputasi perusahaan dan membangun brand awarness yang kuat. Apabila strategi pemasaran internasional dapat berjalan sukses, hal tersebut akan membawa keuntungan pemasaran tertentu, seperti biaya pemasaran yang lebih rendah ketika telah muncul banyak pelanggan baru dan rata - rata perdagangan naik. Dalam kegiatan bisnis internasional ini, memungkinkan bagi Shopee untuk melakukan pertukaran perdagangan internasional dan menjadi jembatan antara perekonomian domestik dengan perekonomian dunia. Ketika Shopee terjun ke pasar internasional, Shopee memanfaatkan keunggulan komparatif setiap negara.

\section{Kesimpulan}

Kehidupan yang semakin berkembang maju dengan adanya perkembangan teknologi informasi dan komunikasi yang disertai pemanfaatan internet mendorong terjadinya bisnis internasional. Bisnis yang muncul di era sekarang ini harus bisa menjawab kebutuhan para pelanggan karena dalam ekonomi modern, pelanggan memiliki peran dalam menentukan semua kegiatan usaha dan produksi. Pemasaran pada pelanggan menjadi hal yang dapat dilakukan tiap bisnis untuk menangkap apa yang dibutuhkan pasar. Pemasaran internasional pada dasarnya mengacu pada penerapan prinsip, metode, dan teknik pemasaran yang umumnya ditujukan untuk pasar luar negeri. Kunci sukses pemasaran internasional adalah kemampuan bisnis untuk mengidentifikasi kebutuhan dan keinginan pasar utama dan pendistribusian produk maupun layanan pada lingkup bisnis internasional. Dalam persaingan bisnis internasional, penting mempelajari kebiasaan, pola pikir, dan selera konsumen asing yang akan ditembus perusahaan. Strategi pemasaran internasional penting dipelajari karena dapat menentukan keberhasilan perusahaan dalam bisnis internasional. Shopee sebagai salah satu E-Commerce yang telah menembus pasar Asia menerapkan sejumlah taktik strategi pemasaran internasional. Melalui marketing public relations strategy Shopee menggunakan kombinasi antara pull dan pass strategy untuk menumbuhkan loyalitas konsumen. Selain itu juga, program Shopee Streamer Academy menjadi sarana pemasaran internasional Shopee dengan tiga taktiknya antara lain competition (penyelenggaran KPOP Stream Competition); demonstration (penyajian konten seperti product review); dan product placement (pengemasan konten dalam livestream). Pelayanan pada konsumen terkhususnya pengguna aplikasi Shopee juga diperhitungkan, dengan memberikan akses pemesanan dan pembelian produk yang praktis.

\section{BIBLIOGRAFI}

Azlina, Y. (2018). Penenerapan Konsep Marketing Publik Relations Sebagai Strategi Pemasaran Politik Dalam Kampanye Politik. Jurnal Akrab Juara, 3(4), 139-153.Google Scholar

Fonna, N. (2019). Pengembangan Revolusi 
Industri 4.0 dalam Berbagai Bidang. Guepedia. Google Scholar

Haris, R. (2012). Strategi Public Relations Dalam Membangun Citra Kidszona Indonesia Sebagai Wahana Edutainment Anak Di Makassar. Google Scholar

Pradana, M. (2017). Klasifikasi bisnis ecommerce di Indonesia. Google Scholar

Ramadhani ${ }^{a}$, F., \& Anisab, R. (2021). Implementasi Program Shopee Streamer Academy Sebagai Strategi Humas Pemasaran. Jurnal Ilmiah LISKI (Lingkar Studi Komunikasi) Vol, 7(1). Google Scholar

Sholikhah, A. (2016). Statistik deskriptif dalam penelitian kualitatif. KOMUNIKA: Jurnal Dakwah Dan Komunikasi, 10(2), 342-362. Google Scholar
Sugiyono. (2012). Memahami Penelitian Kualitatif. CV. Alfabeta. Google Scholar

Syamsuar, S., \& Reflianto, R. (2019). Pendidikan dan tantangan pembelajaran berbasis teknologi informasi di era revolusi industri 4.0. E-Tech: Jurnal Ilmiah Teknologi Pendidikan, 6(2). Google Scholar

Widuhung, S. (2021). Strategi Marketing Public Relations Petromindo Group Di era Pandemi Covid-19. Jurnal Public Relations (J-PR), 2(1), 1-7. Google Scholar

Yosepha Pusparisa. (2020). Shopee, Penguasa E-Commerce Asia Tenggara. https://databoks.katadata.co.id/datapubli $\mathrm{sh} / 2020 / 10 / 16 /$ shopee-penguasa-ecommerce-asia-tenggara

\section{Copyright holder :}

Sherina Said Mazruk, Nuri Aslami (2022).

First publication right :

Action Research Literate

This article is licensed under: 